\title{
Design and Control Methods of Bidirectional DC-DC Converter for the Optimal DC-Link Voltage of PMSM Drive
}

\author{
Tae-Hoon Kim*, Jung-Hyo Lee ${ }^{\dagger}$ and Chung-Yuen Won**
}

\begin{abstract}
This paper shows the design and control methods of the bidirectional DC-DC converter to generate the proper DC-link voltage of a PMSM drive. Conventionally, because the controllable power of the PWM based voltage source inverter is limited by its DC-link voltage, the DC-DC converter is used for boosted DC-link voltage if the inverter source cannot generate enough operating voltage for the PMSM drive. In this paper, to obtain more utilization of this DC-DC converter, optimal DC-link voltage control for PMSM drive will be explained. First, the process and current path of the DC-DC converter will be illustrated, and a control method of this converter for variable DC-link voltage will then be explained. Finally, an improvement analysis of the optimal DC-link voltage control method, especially on the deadtime effect, will be explained. The DC-DC converter of the proposed control method is verified by the experiments by comparing with the conventional constant voltage control method.
\end{abstract}

Keywords: PMSM drive, Optimally controlled DC-link voltage, Bidirectional DC-DC converter

\section{Introduction}

Research on vehicles that use electrical energy has been carried out to address the depletion of fossil fuel and volatile energy prices. Carrying the battery of low output voltage for light weight and small size, a DC-DC converter is used to obtain enough DC-link voltage to operate the PMSM drives. As shown in Fig.1, this DC-DC converter is located between the battery and the inverter to boost the voltage for sufficient DC-link to operate the PMSM. [1-6]

In the conventional research, the control methods of this DC-DC converter application are generally used for a constant DC-link voltage and the management of regenerative energy [1-2]. Combining a supercapacitor and renewable source increases the efficiency of the motor drive due to the regenerative energy control [3]. Recently, to increase the utilization of this DC-DC converter, the research of an optimal DC-link voltage control method has been carried out. This variable DC-link voltage control reduces the current ripple of the inverter and improves the operation efficiency of the PMSM drive [4-5]. For the conventional DC-DC converter topologies for the optimal DC-link voltage control, full-bridge converter [4] and halfbridge converter [5] topologies are generally used. Halfbridge type DC-DC converters have the advantage of reducing the switching device; however, the output voltage should be more than the input voltage. Therefore, the

$\dagger$ Corresponding Author: Automotive Component R\&D Team, LG Innotek Co., Ltd., Korea. (junghyo.lee@lginnotek.com)

* Maritime R\&D Center, LIG Nex1 Co., Ltd., Korea. (thkim0422@ lignex1.com)

** College of Information and Communication Engineering, Sungkyunkwan University, Korea. (woncy@skku.edu)

Received: September 1, 2013; Accepted: May 19, 2014 controllable optimal DC-link voltage is limited.

On the other hand, full-bridge DC-DC converters have the advantage of having a controllable output voltage less than the input voltage; however, the full-bridge DC-DC converter needs more switching device than the halfbridge type DC-DC converter. Moreover, each switch is discontinuously controlled according to the buck-boost operation modes [4]. The problem of this discontinuous control method illustrated in [4] is that, only one switch controls the regenerating and motoring mode in the fullbridge converter topology. To adapt this control method, detecting the operation mode is essential, and the transition is unavoidable for boost and buck operation. Therefore, the DC-link voltage control performance is deteriorated and complex by the control method of [4].

In this paper, the topology of attaching an additional switch to a general half-bridge type DC-DC converter to extend the controllable output DC-link voltage is first illustrated. Second, the designated DC-DC converter is controlled by only one controller for motoring and regenerating operation modes. Therefore, the proposed control method does not need a detecting operation mode

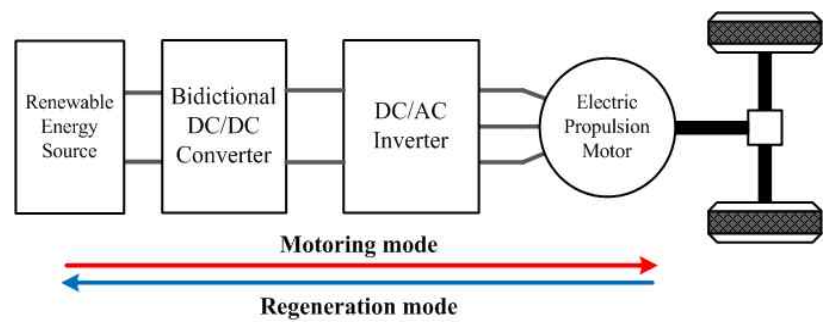

Fig. 1. Bidirectional DC-DC converter using electrical vehicle system. 
and specific transition method for the controlled switch. Third, the analysis of the inverter efficiency improvement with the proposed controlled converter especially on the deadtime effect is explained. Comparison experiments are then performed for the verification of the analyzed improvement.

\section{Design and operation modes of the bidirectional DC-DC Converter}

\subsection{Design of bidirectional DC-DC converter}

Fig. 2 shows the conventional and the semi-full bridge type DC-DC converters used for optimal DC-link voltage control. As aforementioned, in the semi-full bridge converter, a switch is added to the conventional half-bridge converter.

The advantage of this proposed converter is that its controllable range of output voltage is the same as that of the full-bridge converter in motoring operation. However, regenerative operation for the buck mode output voltage is impossible with the proposed converter. In this case, the DC-link voltage is increased because of the regenerative operation of the inverter. However, when the DC-link voltage is more than the input voltage, the regenerative

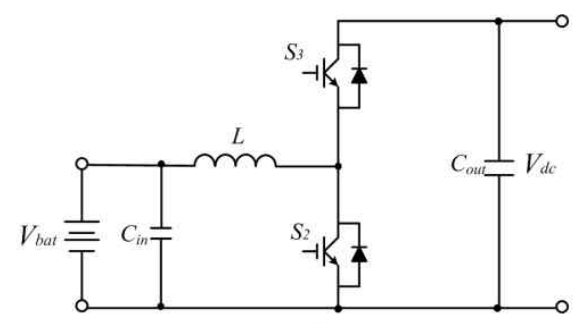

(a)

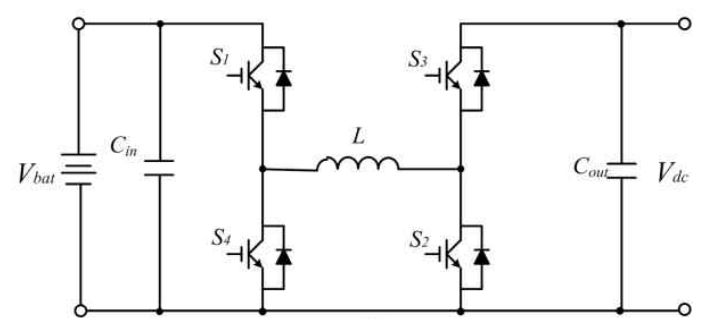

(b)

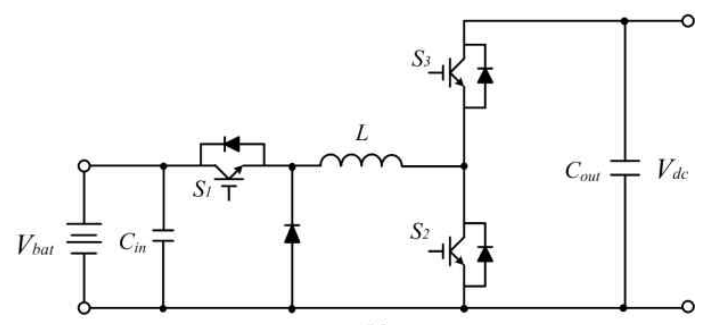

(c)

Fig. 2. Comparison of bidirectional DC-DC converters for optimal DC-link voltage control: (a) half-bridge type; (b) full-bridge type; (c) semi-full bridge type operation is started by the half-bridge arm, and it keeps the DC-link voltage as the input voltage.

In this case, a problem arises in that the semi-full bridge converter cannot control the output voltage to the voltage reference. However, when the DC-link voltage is controlled to be optimal, a low DC-link voltage means that the regenerative output power is also small. In this case, it is better to accumulate regenerative energy on the DC-link capacitor because of the power loss from the current passing through the DC-DC converter. Moreover, in the case of low voltage and high current regenerative power, the conducted and switched power loss is increased by the resistance of the DC-DC converter switches. In this case, accumulating the regenerative energy to DC-link capacitor is more efficient than accumulating the regenerative energy to the battery.

\subsection{Operation modes of bidirectional DC-DC converter}

The Semi-full bridge type DC-DC converter has three operation modes: buck-mode operation, boost-mode operation and regenerative buck-mode operation.

\subsubsection{Buck-mode operation}

Fig. 3 shows the buck-mode operation of the bidirectional DC-DC converter. Switch $S_{I}$ is turned on and off for the general operation of the buck converter topology. In this mode, $S_{3}$ is always turned on and $S_{2}$ is always turned off. The voltage gain of buck-mode is described as follows according to the duty of $S_{l}$.

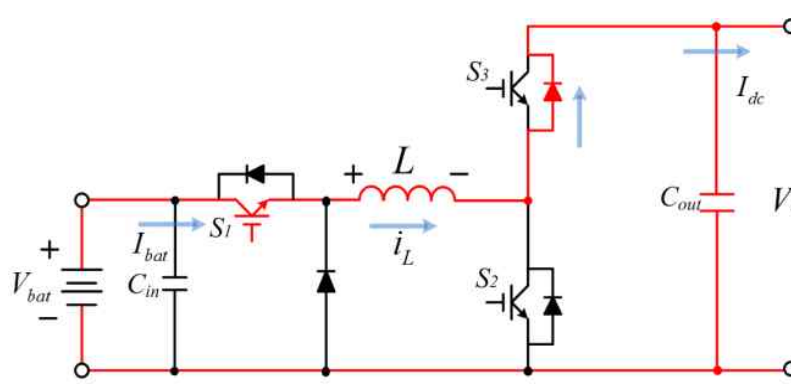

(a) Switch turn-on

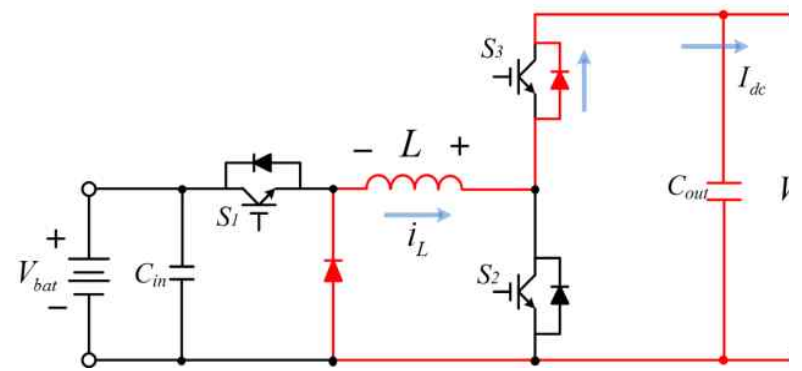

(b) Switch turn-off

Fig. 3. Buck-mode operation according to whether the switch is on or off. 


$$
D_{b u c k}=\frac{V_{d c}}{V_{b a t}}=\frac{I_{b a t}}{I_{d c}} \quad\left(V_{d c}<V_{b a t}\right)
$$

The current and voltage ripples of this mode are illustrated in [1]. As illustrated on [1], these ripples are greater than buck-mode operation. Note that the inductor and capacitor of this converter should be determined by the allowable ripple amount of buck mode. Therefore, and capacitor can be obtained as following Eqs. [11]

$$
L_{\min }=\frac{V_{b a t} T_{s}}{4 \Delta i}, \quad C_{\min }=\frac{V_{b a t} T_{s}^{2}}{16 L_{\min } \Delta v}
$$

where, $\Delta i, \Delta v$ are allowable current and voltage ripple, respectively, $T_{s}$ is switching period.

\subsubsection{Boost-mode operation}

Fig. 4 shows the boost mode operation. As shown in the figure, boost mode operation is affected by the $S_{2}$. Switch $S_{1}$ should be always turned on at this mode, and $S_{3}$ should be complementarily operated from $S_{2}$. The voltage gain of the boost mode is obtained by the following equations.

$$
D_{b o o s t}=1-\frac{V_{b a t}}{V_{d c}}=1-\frac{I_{d c}}{I_{b a t}} \quad\left(V_{d c}>V_{b a t}\right)
$$

From (3), as the duty ratio of $S_{2}$ increases, the voltage gain increases similarly to the general boost converter. However, due to the complementary switching of $S_{3}$, instantaneous transition of the regenerative and generative

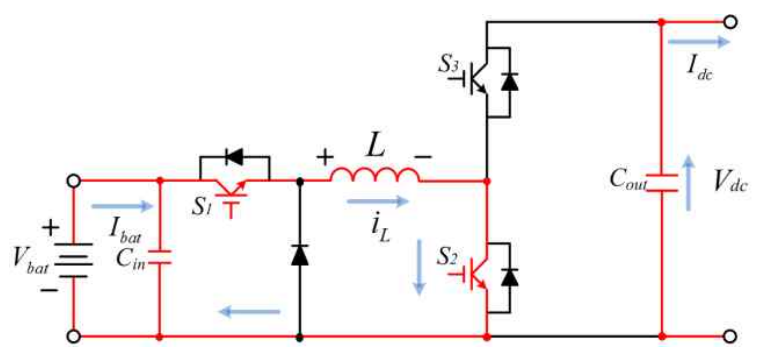

(a) Switch turn-on

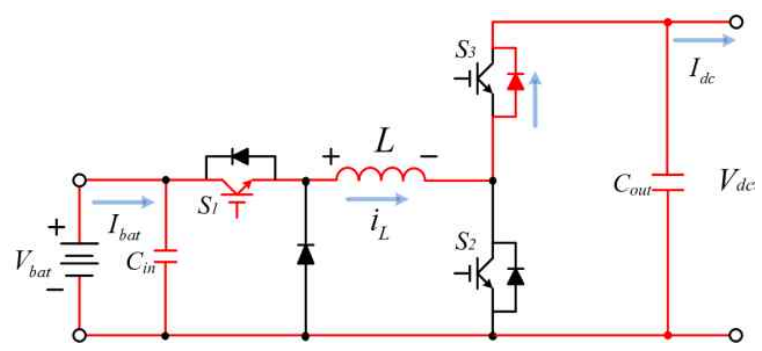

(b) Switch turn-off

Fig. 4. Boost-mode operation according to whether the switch is on or off. operation is achieved. Regenerative operation analysis will be explained in the next chapter.

\subsubsection{Regenerative buck-mode operation}

Fig. 5 shows the regenerative buck mode operation where the regenerative current flows to the battery by the switch of $S_{3}$ operation. The following equation is described by the voltage gain according to the duty of $S_{3}$.

$$
D_{\text {regen_boost }}=1-D_{\text {boost }}=\frac{V_{b a t}}{V_{d c}}=\frac{I_{d c}}{I_{b a t}}\left(V_{d c}>V_{b a t}\right)
$$

As shown in (4), voltage gain is the same as the buck converter operation. If the duty of $S_{3}$ is increased, regenerative energy also increases.

\section{Proposed Control Method of Bidirectional DC-DC Converter for Optimal DC-link Voltage}

Fig. 6 shows the proposed overall control block diagram, which is briefly composed of the inverter control block and the DC-DC converter control block diagram. Among these, the inverter control block uses the general vector control method.

The proposed DC-DC converter control block diagram is composed of the voltage reference generator for the optimal DC-link voltage of the PMSM drive, the DC-link voltage controller, and the PWM generator for the DC-DC converter switch control according to the operation modes illustrated in chapter 2 .

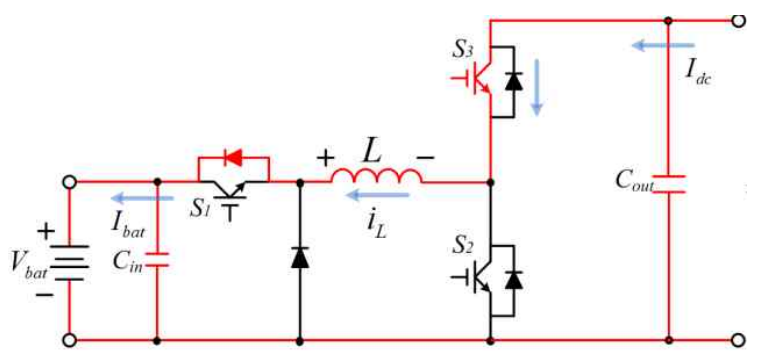

(a) Switch turn-on

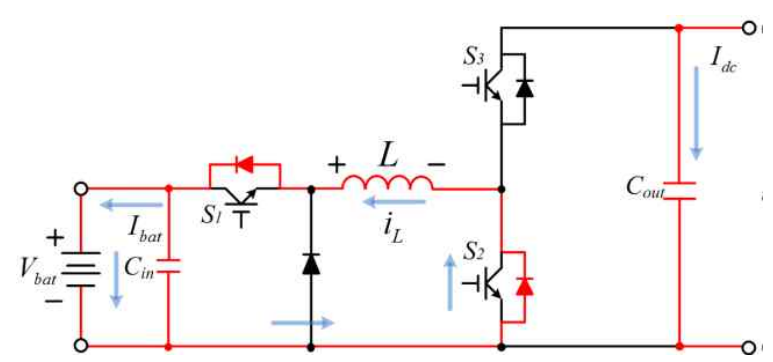

(b) Switch turn-off

Fig. 5. Regenerative buck-mode operation according to whether the switch is on or off. 


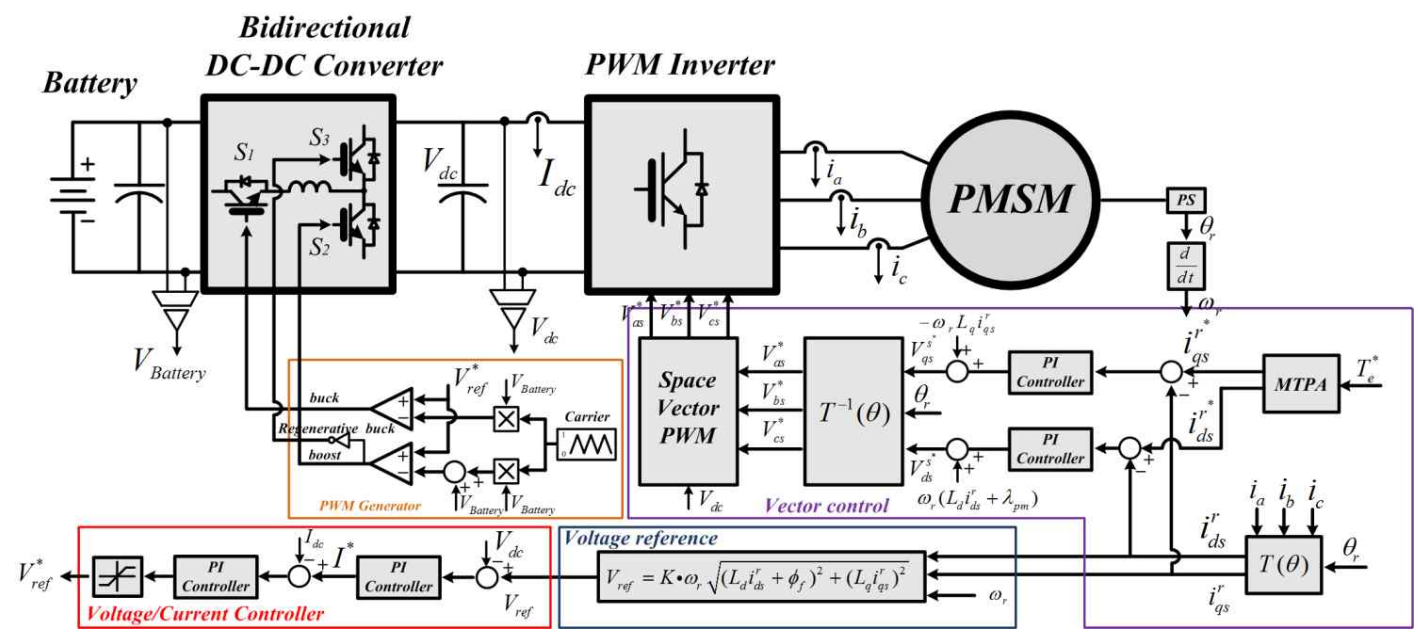

Fig. 6. Overall control block diagram for optimal DC-link voltage

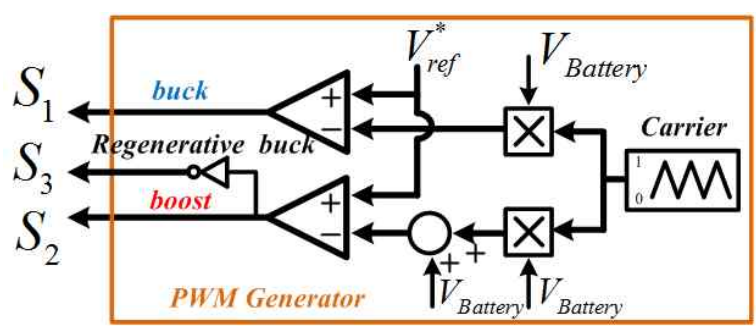

Fig. 7. Proposed PWM Generator for controlling the bidirectional power operations

\subsection{Proposed PWM Generator for affection the input voltage}

As shown in Fig. 7, the peak value of the carrier varies according to the battery voltage, which is the input of the DC-DC converter. To operate for buck mode, if the voltage controller output is less than the input battery voltage, the voltage reference is compared with the carrier which value is from zero to the battery voltage. And then, the output duty $D_{\text {buck }}$ controls the switch $S_{1}$. During this operation, switch $S_{2}$ and $S_{3}$ should be turned off and turned on, respectively. To achieve this operation, the lower carrier wave for boost mode operation has an offset, the amount of which is the input battery voltage. Therefore, the lower carrier has a value from the battery voltage to twice the battery voltage. This configuration of the carrier keeps the duty $D_{\text {boost }}$ for $S_{2}$ turned on and the duty $D_{\text {regen_boost }}$ for $\mathrm{S}_{3}$ turned off during the buck-mode operation.

On the other hand, the boost and regenerative buck mode operation is activated when the DC-link voltage is more than the battery voltage as aforementioned in Chapter II. Because these modes are always complementarily operated, the duty of $S_{2}$ and $S_{3}$ is configured as $D_{\text {regen_boost }}=\bar{D}_{\text {boost }}$. During these modes, switch $S_{I}$ is always high due to the configuration of proposed PWM generator. This switch operation is used for the bidirectional power flow of the boost and the regenerative buck

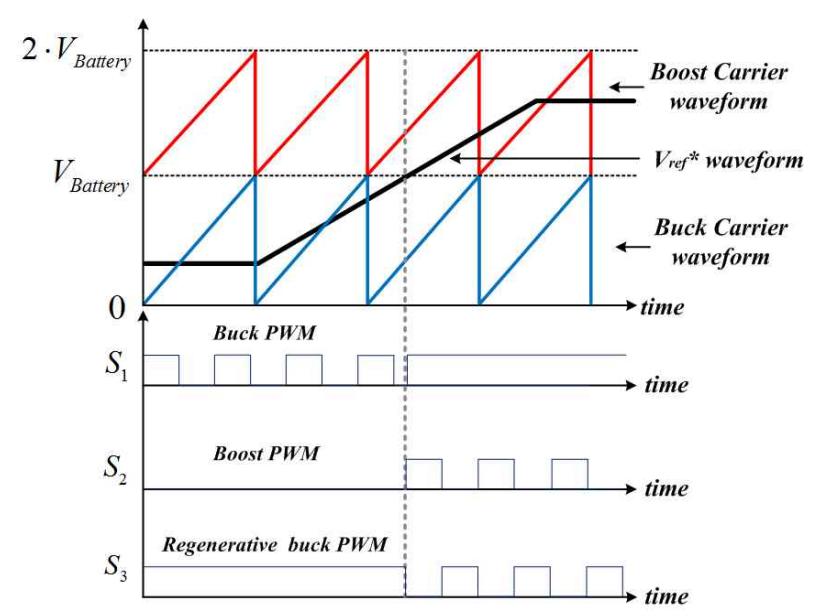

Fig. 8. Carrier and reference voltage composition for PWM switching

operations. Fig. 8 shows the PWM generator operation of Fig. 7 according to the controller output voltage reference. The switching operation illustrated in chapter 2 is achieved by the proposed PWM generator as shown in the figure.

As aforementioned, in the case of the buck operation, the voltage reference is increased until the output voltage reaches the input voltage. In this case, the regenerative buck PWM switch is always high and the boost PWM switch is off. When the voltage reference is more than input voltage, buck PWM switch is always high, at the same time, the boost PWM switch and the regenerativebuck PWM switch are complementarily switching for boosted output voltage.

\subsection{Effect of the optimal DC-link voltage control on the SVPWM duty}

If the inverter generates pure ac voltage, an increase of the output voltage results in extending the controllable region without the current ripple. However, because 
general control method for the inverter uses the PWM switching, the excessive DC-link voltage increases the current ripple of PMSM.

The steady state of a phase current ripple by the PWM is calculated using the following equations.

$$
\begin{aligned}
& \frac{d i_{a}}{d t}=\left\{\begin{array}{l}
\frac{\frac{1}{3} V_{d c} \operatorname{sign}\left(S_{a}\right)-E_{a} \sin (\delta)-R_{s} i_{a}}{L_{s}}\left(-60^{\circ}<\delta<60^{\circ} \text { or } 120^{\circ}<\delta<240^{\circ}\right) \\
\frac{\frac{2}{3} V_{d c} \operatorname{sign}\left(S_{a}\right)-E_{a} \sin (\delta)-R_{s} i_{a}}{L_{s}}\left(60^{\circ}<\delta<120^{\circ} \text { or } 240^{\circ}<\delta<300^{\circ}\right)
\end{array}\right. \\
& \left(\therefore \operatorname{sign}\left(S_{a}\right)=\left\{\begin{array}{c}
1\left(S_{a}=1\right) \\
-1\left(S_{a}=0\right)
\end{array}\right)\right. \\
& E_{a}=\left|V_{d}+V_{q}\right| \\
& V_{d}=-\omega_{r} L_{q} i_{q s}^{r}, V_{q}=\omega_{r}\left(L_{d} i_{d s}^{r}+\varphi_{f}\right) \\
& {\left[\begin{array}{c}
i_{d s}^{r} \\
i_{q s}^{r}
\end{array}\right]=\left[\begin{array}{ccc}
\cos \theta_{r} & \cos \left(\theta_{r}-\frac{2}{3} \pi\right) & \cos \left(\theta_{r}+\frac{2}{3} \pi\right) \\
-\sin \theta_{r} & -\sin \left(\theta_{r}-\frac{2}{3} \pi\right)-\sin \left(\theta_{r}+\frac{2}{3} \pi\right)
\end{array}\right]\left[\begin{array}{l}
i_{a} \\
i_{b} \\
i_{c}
\end{array}\right]}
\end{aligned}
$$

where $S_{a}$ is the switching function, $L_{s}$ is a phase inductance, $R_{s}$ is a phase resistance, $\delta$ is the voltage angle, $\omega_{r}$ is motor speed, $L_{d}$ is the d-axis inductance, $L_{q}$ is the q-axis inductance, and $\theta_{r}$ is rotor position.

From the equations, a phase current ripple by PWM is determined by the DC-link voltage, the speed of PMSM, and the phase current magnitude. Therefore, a phase current ripple can be reduced when there is a small voltage difference between the DC-link voltage and the back-EMF magnitude of the motor. The optimum voltage of DC-link used in this paper is described as (7).

$$
V_{r e f}=K \cdot \omega_{r} \sqrt{\left(L_{d} i_{d s}^{r}+\varphi_{f}\right)^{2}+\left(L_{q} i_{q s}^{r}\right)^{2}}
$$

In (7), the gain $K$ is set as $\sqrt{3}$ for linear modulation of the SVPWM. From this equation, the effective and zero vectors of the SVPWM are obtained using the following equations.

$$
\begin{aligned}
V_{d c} & =\sqrt{3} V_{r e f} \\
T_{1} & =T_{s} \cdot \frac{V_{r e f}}{2 V_{d c} / 3} \frac{\sin \left(60^{\circ}-\delta\right)}{\sin 60^{\circ}} \\
& =T_{s} \cdot \frac{\sqrt{3}}{2} \frac{\sin \left(60^{\circ}-\delta\right)}{\sin 60^{\circ}}=T_{s} \sin (60-\delta) \\
T_{2} & =T_{s} \cdot \frac{V_{r e f}}{2 V_{d c} / 3} \frac{\sin (\delta)}{\sin 60^{\circ}} \\
& =T_{s} \cdot \frac{\sqrt{3}}{2} \frac{\sin (\delta)}{\sin 60^{\circ}}=T_{s} \sin (\delta) \\
T_{0} & =T_{s}-\left(T_{1}+T_{2}\right)
\end{aligned}
$$

As shown in the equations, when the DC-link voltage is

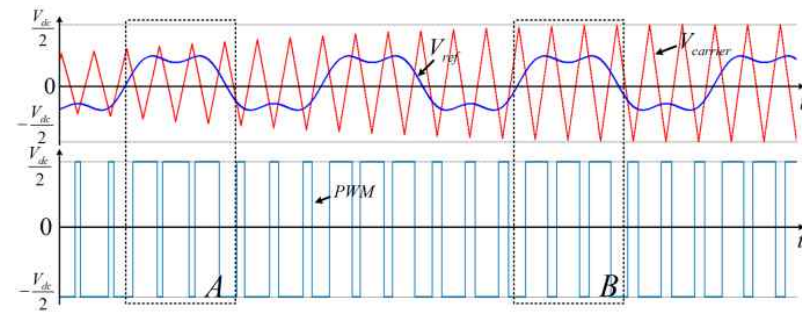

Fig. 9. SVPWM switching with the varied DC-link voltage

controlled by the optimal value as (7), the variation of the voltage reference magnitude disappears on the vectors of the SVPWM. These equations mean that the ratio of the fundamental component and the ripple component from the current controller can be fixed regardless of the modulation amplitude. The problem using the conventional fixed DC-link voltage is that the current ripple affected by the voltage reference is magnified at the low modulation amplitude. In contrast, with the proposed control method, the affect of the ripple component is fixed regardless of the modulation amplitude.

Fig. 9 shows the SVPWM switching with the varied DC-link voltage. As shown in this figure, despite the fixed phase voltage reference magnitude, the modulation amplitude is varied because the peak value of the carrier is varied by the DC-link voltage. If the DC-link voltage is small, the PWM duty is increased as the circumstance A. In contrast, if the DC-link voltage is high, the duty is decreased as the circumstance $\mathrm{B}$. This means that the output power can be controlled by the DC-link voltage, even though the modulation amplitude of the SVPWM is optimally fixed.

\subsection{Reduction of the deadtime effect by the optimal DC-link voltage}

Fig. 10 shows the distorted output voltage from the deadtime in the PWM inverter operation. Assuming that the varied voltage reference can be ignored during the switching period, the inverter output voltage, which is the PWM duty from the SVPWM voltage reference, is reduced by the deadtime.

Reduced duty variation can be easily compensated by the constant switch on-off operation. However, the distorted voltage is varied according to the direction of the phase current, and this distorted voltage is expressed as follows.

$$
\begin{array}{ll}
\Delta V=\frac{-T_{d}-T_{\text {on }}+T_{\text {off }}}{2 T_{s}} V_{d c_{-} \text {rate }}, & i_{s}>0 \\
\Delta V=\frac{T_{d}+T_{\text {on }}-T_{\text {off }}}{2 T_{s}} V_{d c_{\text {_rate }},}, & i_{s}<0
\end{array}
$$

where $T_{d}$ is deadtime, $T_{\text {on }}$ is switch-on time, and $T_{\text {off }}$ is switch-off time.

From this voltage error, the harmonic current ripple can 


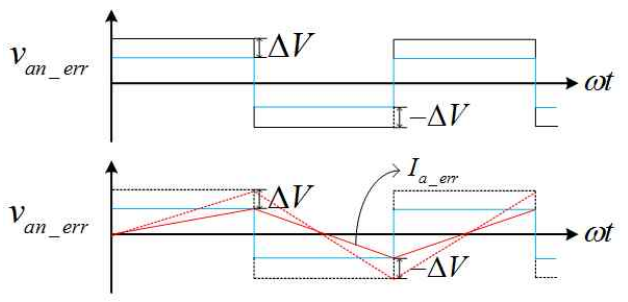

Fig. 10. Deadtime effect of PWM inverter

be described as follows [7].

$$
\begin{aligned}
I_{d s_{-} e r r}^{e}= & \frac{4}{\pi} \frac{\Delta V}{Z_{L}}\left(-\sin \varphi+\frac{1}{5} \sin \left(6 \omega_{r} t-5 \varphi\right)+\frac{1}{7} \sin \left(6 \omega_{r} t-7 \varphi\right)\right. \\
& \left.+\frac{1}{11} \sin \left(12 \omega_{r} t-11 \varphi\right)++\frac{1}{13} \sin \left(12 \omega_{r} t-13 \varphi\right) \ldots\right) \\
I_{q s_{-} e r r}^{e}= & \frac{4}{\pi} \frac{\Delta V}{Z_{L}}\left(-\cos \varphi+\frac{1}{5} \cos \left(6 \omega_{r} t-5 \varphi\right)-\frac{1}{7} \cos \left(6 \omega_{r} t-7 \varphi\right)\right. \\
& \left.+\frac{1}{11} \cos \left(12 \omega_{r} t-11 \varphi\right)-\frac{1}{13} \cos \left(12 \omega_{r} t-13 \varphi\right) \ldots\right)
\end{aligned}
$$

where $Z_{L}$ is the motor impedance and $\varphi$ is the difference between the voltage and current angle.

From (13), the phase and dq-axis currents have the 6 th harmonic component by the deadtime. Conventional research for reducing this effect has been developed [7-10]. The most common deadtime compensation method is the deadtime of each switches are differently applied according to the phase current direction [8]. However, this method needs a Zero Crossing Circuit (ZCC) for detecting the direction of the phase current, and the detecting error occurs at a nearly zero point of the phase current because of the sensing ripple. On the other hand, a compensation method for the voltage which derives from the deadtime effect has been developed [7]. This method is based on the fact that the harmonic caused by the deadtime effect is a specific component according to the rotor position. Therefore, it can be compensated by extracting the current ripple component by the PLL from the rotor position. However, this method is affected by the correctness of the feedforward term of the current controller. Besides, this compensation voltage is affected by the anti-windup of the current controller.

With the proposed varied DC-link voltage control method, the error voltage from deadtime is described in the following equations.

$$
\begin{array}{ll}
\Delta V=\frac{-T_{d}-T_{o n}+T_{o f f}}{2 T_{s}} \sqrt{3} V_{r e f}, & i_{s}>0 \\
\Delta V=\frac{T_{d}+T_{o n}-T_{o f f}}{2 T_{s}} \sqrt{3} V_{r e f}, & i_{s}<0 \\
\sqrt{3} V_{r e f}<V_{d c_{-} r a t e} &
\end{array}
$$

Because the inverter current for the PMSM drive exists as (5), which is the integration of the voltage difference between the inverter and the back-EMF, the deadtime effect can be removed on the phase current if the DC-link voltage is controlled to be perfectly optimal. Practically, the deadtime effect cannot be totally removed by the optimally controlled DC-link voltage because the modulated voltage from the SVPWM is varied according to the voltage angle, despite having the same magnitude as the reference voltage.

Because none of the conventional methods reduce the deadtime effect, but rather compensates it, this effect remains on the phase current in the case of specific motor parameters or operating circumstances. Moreover, if the error is too large to compensate, these compensation methods can no longer retain the deadtime ripple component. As a result, in contrast to conventional methods, due to the optimally controlled DC-link voltage, proposed method reduces the deadtime effect regardless of the motor parameters.

\section{Experimental results}

Tables 1 and 2 show the parameters used in the experiment. The control frequency of the DC-DC converter is $20[\mathrm{kHz}]$ and that of the inverter is 10 [kHz], respectively.

Fig. 11 shows the experimental setup. As shown in the figure, the experimental setup is composed of the MG-set and the DC-DC converter. The MG-set is composed of the test PMSM and induction motor for the load. The source of the load motor is from 3-ph of the AC-source, which is regulated by the AC-DC PWM converter. The source of the proposed DC-DC converter is from the series connected lead-acid batteries and its voltage is 98 [V].

The inductor and capacitor of the proposed DC-DC

Table 1. Parameters of the converter

\begin{tabular}{c|c}
\hline Parameter & Value \\
\hline Input voltage & $96[\mathrm{~V}]$ \\
\hline Output voltage & $250[\mathrm{~V}]$ \\
\hline Input current & $40[\mathrm{~A}]$ \\
\hline Main inductor & $739.2[\mu \mathrm{H}]$ \\
\hline Main capacitor & $260.4[\mu \mathrm{F}]$ \\
\hline Switching frequency & $20[\mathrm{kHz}]$ \\
\hline
\end{tabular}

Table 2. Parameters of the PMSM

\begin{tabular}{c|c}
\hline Parameter & Value \\
\hline Rated power & $10[\mathrm{~kW}]$ \\
\hline Rated torque & $20[\mathrm{Nm}]$ \\
\hline Rated DC-link voltage & $250[\mathrm{~V}]$ \\
\hline Phase current & $62[\mathrm{Arms}]$ \\
\hline d-axis inductance & $0.848[\mathrm{mH}]$ \\
\hline q-axis inductance & $1.484[\mathrm{mH}]$ \\
\hline Phase resistance & $30[\mathrm{~m} \Omega]$ \\
\hline Pole & $16[\mathrm{pole}]$ \\
\hline Rated speed & $2400[\mathrm{rpm}]$ \\
\hline
\end{tabular}




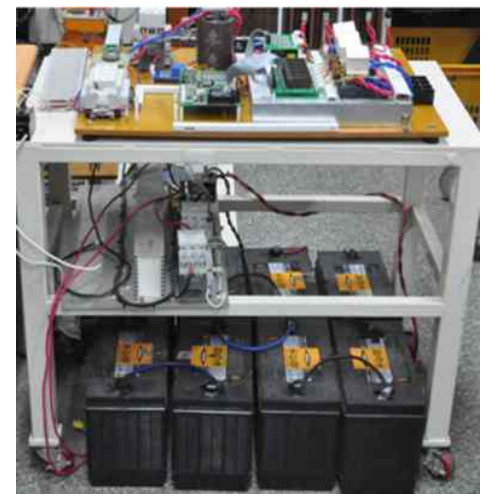

(a)

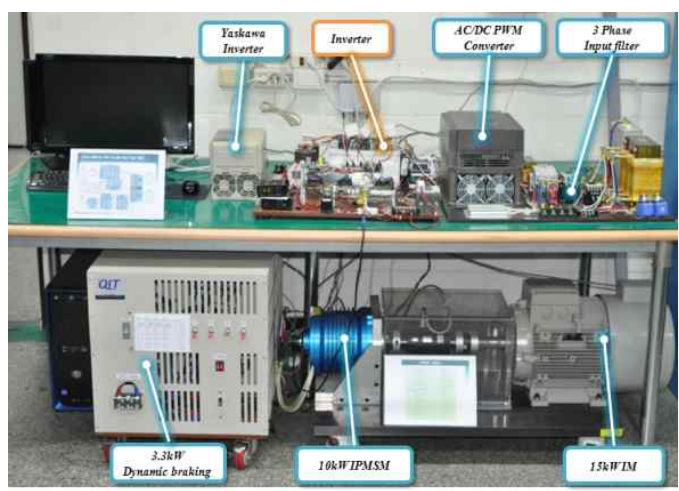

(b)

Fig. 11. Experimental setup: (a) DC-DC converter setup; (b) MG-set.

converter is designed so that the current ripple is 2 [A] and the voltage ripple is $5[\mathrm{~V}]$. However, because the calculated capacitance does not consider the ESR(Equivalent Series Resistor), capacitor is selected by experimental trial and error to satisfy the voltage ripple.

As aforementioned in chapter II, this limitation is determined on the buck-operation region. In the boost operation, the voltage and current ripples are reduced because a higher voltage to regulate the current is alternately applied to the inductor.

Fig. 12 shows the experimental result of the optimal DClink voltage control method according to the motor speed and dq-axis currents. In the case where the motor speed and load torque are zero, theoretically, the necessary DClink voltage is also zero.

However, the limitation of the minimum DC-link voltage is needed for initial operation current control. In this paper, this minimum limitation is set as 50 [V]. Because this target voltage is on the buck mode operation, the output voltage has the ripple of the designed DC-DC converter parameter. However, in boost mode operation, the voltage ripple is hardly seen because of the aforementioned alternative boost and regenerative buck operation. As shown in the figure, the DC-link voltage is increased according to the motor speed. In this case, the DC-link voltage starts to increase when the calculated

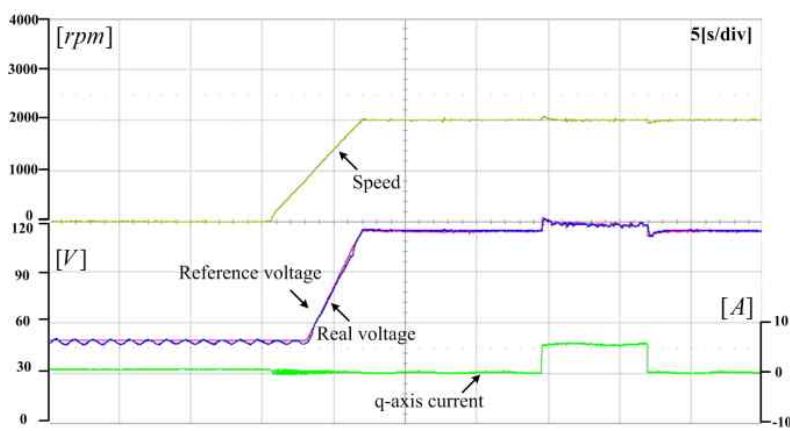

(a)

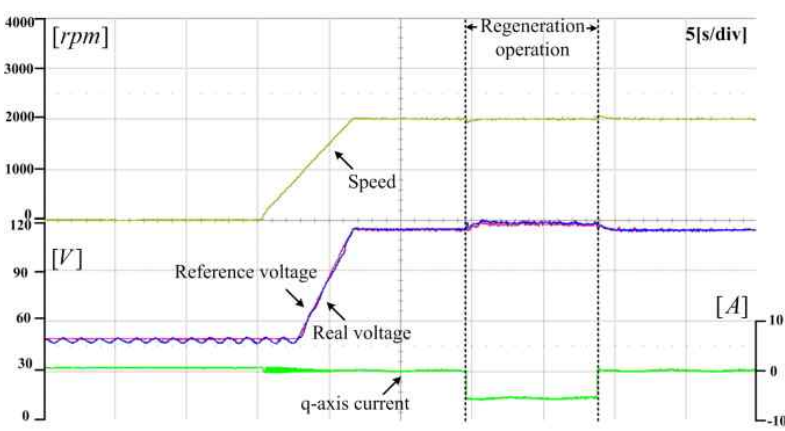

(b)

Fig. 12. Experimental results of the optimal DC-link voltage control: (a) motoring operation; (b) Regenerating operation

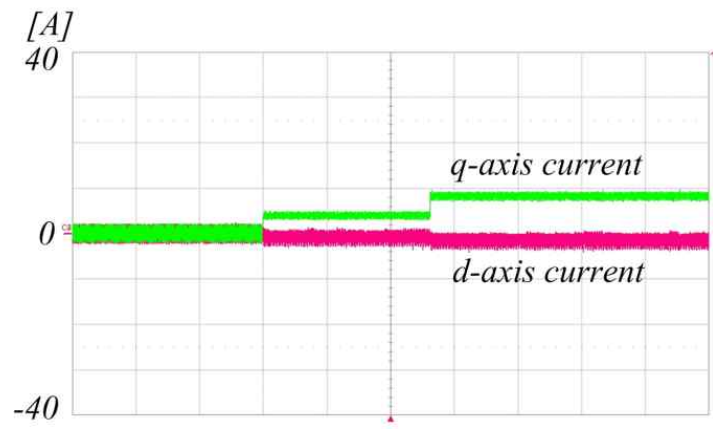

(a)

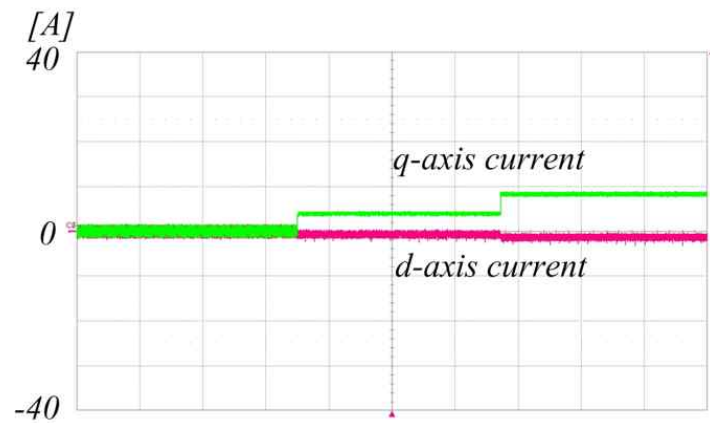

(b)

Fig. 13. Comparison of the dq-axis currents ripple: (a) Conventional fixed DC-link voltage; (b) Proposed varied DC-link voltage. 
optimal DC-link voltage is more than the minimum limitation voltage.

During the target speed of 2000 [rpm] operation, the torque reference of $5[\mathrm{Nm}]$ is applied to the PMSM to generate this torque. The generated torque increases the DC-link voltage because of the back-EMF from the applied dq-axis currents. The increased DC-link voltage occurs in both the regenerating and motoring operations.

Fig. 13 shows a comparison of the dq-axis currents between the conditions of the rated DC-link voltage and the optimally controlled DC-link voltage. As shown in the figure, the current ripple is reduced by the proposed control method. In the case of the constant DC-link voltage, the current ripple is increased when the controlled current value is low. The reason for this phenomenon is that the current ripple of the inductance load is increased when the gap of the applied voltage and back-EMF is large. However, with the proposed control method, the current ripple is reduced because of the small voltage gap.

Fig. 14 shows the comparison result of the deadtime effect between the rated DC-link voltage and the proposed varied DC-link voltage. The applied deadtime is 5 [us] in both cases. When the rated DC-link voltage is applied, the 6th harmonics of the phase current is comparatively large because of the excessive deadtime. However, the effect of the deadtime is reduced with the proposed control method as shown in the figure. The THD of the conventional method is $7[\%]$; however, with the optimal DC-link voltage

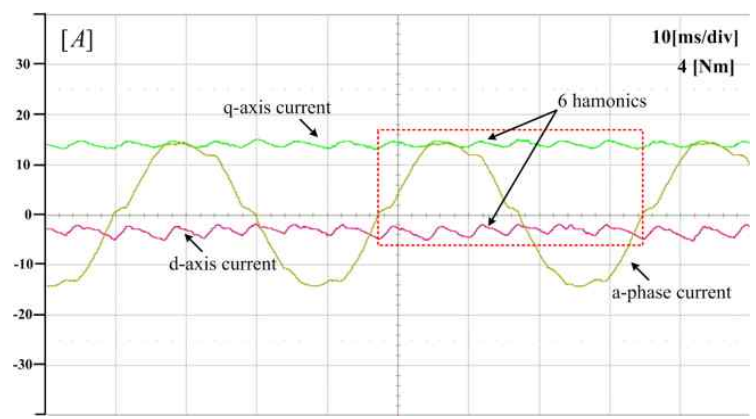

(a)

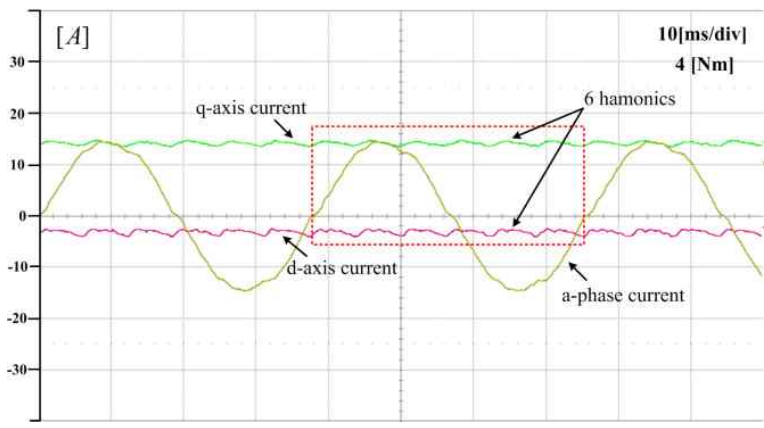

(b)

Fig. 14. Comparison of the phase current ripple: (a) Conventional DC-link voltage control condition; (b) Proposed DC-link voltage control condition control method, the THD can be reduced to 5.6[\%].

Fig. 15 shows the comparison of the deadtime compensation effect. The excessive deadtime makes the phase current has large amount of harmonics as shown in Fig. 15(a). With the general deadtime compensation method of [8], the phase current is more sinusoidal than the Fig. 15(a) as described on Fig. 15(b). However, with the varied DClink voltage condition, not only the deadtime effect is reduced, but also the current ripple is reduced as shown on Fig. 15(c).

Table 3 shows the efficiency comparison of the conventional and proposed DC-link voltage condition. The applied deadtime is 5[us]. In the proposed control method, the DC/DC converter operates in buck mode at $500[\mathrm{rpm}]$, and boost mode at $2500[\mathrm{rpm}]$. In conventional method,

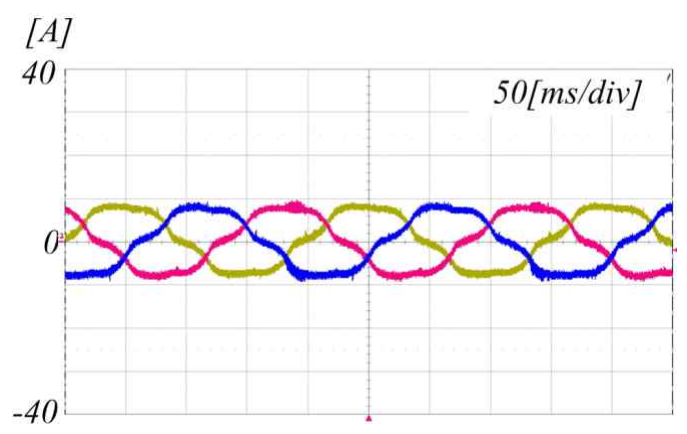

(a)

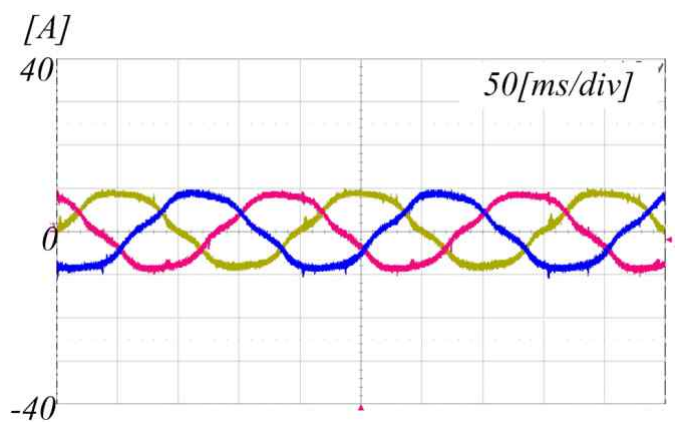

(b)

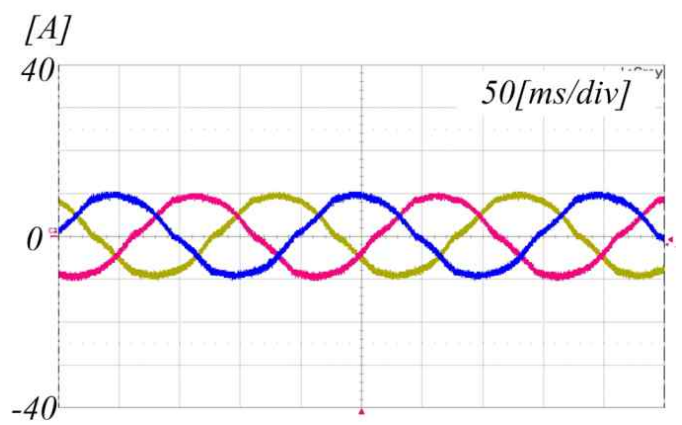

(c)

Fig. 15. Comparison of the deadtime compensation: (a) Conventional DC-link voltage control condition with no deadtime compensation; (b) Conventional DC-link voltage control condition with deadtime compensation; (c) Proposed DC-link voltage control condition with deadtime compensation. 
Table 3. The efficiency comparison of the conventional and proposed DC-link voltage condition

\begin{tabular}{|c|c|c|c|c|c|c|}
\hline Operation Speed & Generated Torque & Generated Power & Converter operation & Converter efficiency & Inverter efficiency & Total efficiency \\
\hline \multirow{4}{*}{$\begin{array}{c}500 \\
{[\mathrm{rpm}]}\end{array}$} & \multirow{2}{*}{$5[\mathrm{Nm}]$} & \multirow{2}{*}{$\begin{array}{c}5.2[\%] \\
\text { of Rated Power } \\
\end{array}$} & Fixed voltage & $84[\%]$ & $84[\%]$ & $71[\%]$ \\
\hline & & & Variable voltage & $80[\%]$ & $88[\%]$ & $70[\%]$ \\
\hline & \multirow{2}{*}{$20[\mathrm{Nm}]$} & \multirow{2}{*}{$\begin{array}{c}20.8[\%] \\
\text { of Rated Power }\end{array}$} & Fixed voltage & $88[\%]$ & $87[\%]$ & $77[\%]$ \\
\hline & & & Variable voltage & $83[\%]$ & $95[\%]$ & $79[\%]$ \\
\hline \multirow{4}{*}{$\begin{array}{c}2000 \\
{[\mathrm{rpm}]}\end{array}$} & \multirow{2}{*}{$5[\mathrm{Nm}]$} & \multirow{2}{*}{$\begin{array}{c}20.8[\%] \\
\text { of Rated Power }\end{array}$} & Fixed voltage & $87[\%]$ & $89[\%]$ & $77[\%]$ \\
\hline & & & Variable voltage & $86[\%]$ & $92[\%]$ & $79[\%]$ \\
\hline & \multirow{2}{*}{$20[\mathrm{Nm}]$} & \multirow{2}{*}{$\begin{array}{c}83.3[\%] \\
\text { of Rated Power }\end{array}$} & Fixed voltage & $92[\%]$ & $94[\%]$ & $86[\%]$ \\
\hline & & & Variable voltage & $92[\%]$ & $97[\%]$ & $89[\%]$ \\
\hline
\end{tabular}

all results are obtained at the rated DC-link voltage condition. As shown on the table, the total efficiency is almost same because increased inverter efficiency is counterbalanced by the DC/DC converter efficiency. It is caused by the efficiency of the buck mode operation which has comparatively lower efficiency than the boost mode operation. Despite of this problem, it can be overcome by adapting ZVZCS(Zero Voltage Zero Current Switching) resonant converter. Moreover, the improvement of inverter efficiency at overall operating area has many advantages in the traction system for the robust control and noise problem.

\section{Conclusion}

This paper illustrates the design and control methods of bidirectional DC-DC converter for the optimal DClink voltage of PMSM drive. To control the DC-link voltage optimally, the DC-link voltage is controlled by the reference considers the back-EMF voltage of PMSM.

The DC-DC converter topology is composed to operate buck, boost and regenerative-buck for wide controllable voltage. To control these operations with smooth transition, the PWM generator consists of double carriers affected by the input voltage is proposed. Also, the analysis of optimally controlled DC-link voltage on PMSM drive, especially on the improvement of deadtime effect is illustrated in this paper.

Many comparison experiments are performed for verifying the proposed control algorithm and analysis. These results show that the optimally controlled DC-link voltage makes to reduce the d-q axis current ripples on low speed and high current operation. Although the total efficiency improvement is insufficient, high performance motor drive due to the reduction of $d-q$ axis current ripple can give many advantages for $\mathrm{EV} / \mathrm{HEV}$ traction system using the bidirectional DC/DC converter.

\section{References}

[1] F. Caricchi, F. Serra, G. Tani, L. Solero, "Study of bidirectional buck-boost converter topologies for application in electrical vehicle motor drive,'IEEE APEC 1998, vol. 11, no. 5, pp. 287-293, Feb, 1998.

[2] R. M. Schupbach, J. C. Balda, "Comparing DC-DC Converters for Power Management in Hybrid Electric Vehicles," IEEE IEMDC 2003, pp. 1369 1374, Jun. 2003.

[3] Jian Cao, Ali Emadi, “A New Battery/UltraCapacitor Hybrid Energy Storage System for Electric, Hybrid, and Plug-In Hybrid Electric Vehicles", IEEE Trans. on Pow. Elec., vol. 27, no. 1, pp. 122-132,JAN. 2012.

[4] Abculmotin Howlader, Naomitsu Urasaki, Tomonobu Senjyu, Atsushi Yona, and Ahmed Yousuf Svber. "Optimal PAM Control for a Buck Boost DC-DC Converter with a Wide-Speed-Range of Operatrion for a PMSM" Journal of Power Electronics, vol. 10, no. 5, pp. 491-497, 2010.

[5] Estima, J.O., Marques Cardoso, A.J., "Efficiency Analysis of Drive Train Topologies Applied to Electric/ Hybrid Vehicles", IEEE Trans. on Vehi. Tech., vol. 61, no. 3, pp. 1021-1031, Mar. 2012.

[6] F.Blaabjerg, J.K.Person, P. Thoegersen, "Improved modulation techniques for PWM-VSI for PMSM" IEEE Trans. Ind. Electron., vol. 1, pp. 87-95, 1997.

[7] Seon-Hwan Hwang; Jang-MokKim, "Dead Time Compensation Method for Voltage-Fed PWM Inverter" IEEE Trans. Ener. Conv., vol. 25, no. 1, pp. 1-10, Mar. 2010.

[8] J. -W. Choi and S.-K. Sul "Inverter output voltage synthesis using novel dead time compensation", IEEE Trans. Power Electron., vol. 11, no. 2, pp. 221227, 1996.

[9] S. -G. Jeong and M.-H. Park "The analysis and compensation of dead-time effects in PWM inverters", IEEE Trans. Ind. Electron., vol. 38, no. 2, pp.108-114 1991.

[10] T. Sukegawa, K. Mizuno, T. Matsui and T. Okuyama "Fully digital, vector controlled PWM VSI-fed ac drives with an inverter dead-time compensation strategy", IEEE Trans. Ind. Appl., vol. 27, no. 3, pp. $552-5591991$.

[11] N. Mohan, "Power Electronics", John Wiley \& Sons, Inc, 2003. 


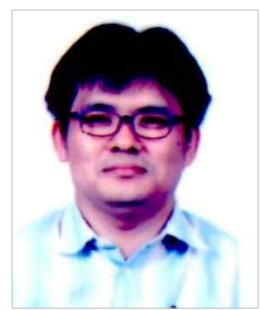

Tae-Hoon Kim He received the B.S. and M.S. degrees in electrical engineering from Sungkyunkwan University, Suwon, Korea, in 1988 and 1990, respectively. From 1995, he joined LG precision, and currently, he is a research engineer of Maritime R\&D center in LIG Nex1. His research interests include power electronics for military application.

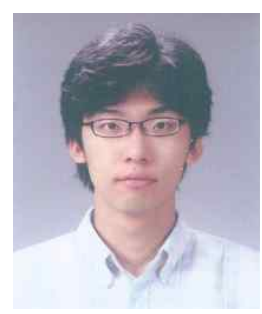

Jung-Hyo Lee He received the B.S. degree in electrical engineering from Konkuk University, Seoul, Korea, in 2006, and the M.S. and the Ph.D. degrees in electrical engineering from Sungkyunkwan University, Suwon, Korea, in 2008 and 2013, respectively. From 2013, He has been a senior researcher of automotive component $R \& D$ Team in LG Innotek. His research interests include converters and inverters for motor drive application.

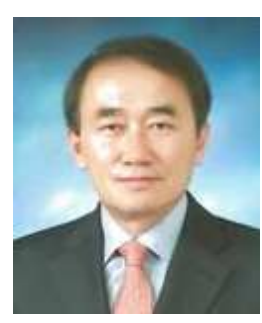

Chung-Yuen Won He received the B.S. degree in electrical engineering from Sungkyunkwan University, Suwon, Korea, in 1978, and the M.S. and Ph.D. degrees in electrical engineering from Seoul National University, Seoul, Korea, in 1980 and 1987, respectively. From 1990 to 1991, he was with the Department of Electrical Engineering, University of Tennessee, Knoxville, as a Visiting Professor. Since 1988, he has been with a member of the faculty of Sungkyunkwan University, where he is a Professor in the College of Information and Communication Engineering. He is also the Director of Samsung Energy Power Research Center. He was the President of the Korean Institute of Power Electronics in 2010. Since 2011, he has been the Director of the Korean Federation of Science and Technology Societies. His current research interests include the power electronic of electric machines, electric / hybrid vehicle drives, and power converters for renewable energy systems. 